\title{
Wives and Mothers At Risk: The Role of Marital and Maternal Status in Criminal Activity and Incarceration
}

\author{
Marianne Berry, Toni Johnson, Margaret Severson, \& Judy L. Postmus
}

\begin{abstract}
As the numbers of women entering prison are increasing, more attention is being paid to the social circumstances of criminally involved women. Crime research has highlighted the familial roles of women more than men, focusing on the social and personal roles of women. This study examines a cross-sectional sample of 423 women in one state, assessing the associations of motherhood and intimate partnership with criminal activity. The study finds that criminal activity, particularly economic crime, is highly related to motherhood. Economic crime is predicted by having a higher number of young children, while both economic and violent crimes are predicted by a woman's history of victimization; marriage does not reduce these risks.
\end{abstract}

E xisting studies indicate that inmates' families are an important source of deterrence to continued criminal offending and recidivism (Covington, 2003; Hairston, 1998, 1991; Richie, 2001). Findings from Slaught's (1999) study also found that family relationships have a strong positive influence on recovery from addictions and alcohol and on drug relapse prevention among parolees. A meta-analysis of the research on best practices with women offenders, completed by Dowden and Andrews (1999), identified family process variables, including concepts such as affection, to be strong predictors of postincarceration success for women.

Recent research, however, indicates that family relationships, specifically motherhood and marriage, may have less than positive influences on the lives of some women offenders. A better understanding of the interplay between those relationships and criminal behavior of women will enable us to identify ways to help women reduce behaviors that put them at risk of arrest and incarceration and stem the rising tide of incarcerated women.

\section{Overview of Women in Prison}

Women account for approximately $7 \%$ of the inmate population and statistically comprise a small percentage of the total population living under some kind of correctional supervision (Harrison \& Beck, 2006). Significantly, the number of women in U.S. jails and prisons has grown steadily over the past 20 years and has outpaced the corresponding percentage of male prisoners (Greenfield \& Snell, 1999; Harrison \& Beck; Stephan, 2001). Most of the women involved in the criminal justice system are poor, undereducated, unskilled, and disproportionately women of color (Beck, 2000; Travis \& Waul, 2003).

A large percentage of these women are also parents to minor children. Estimates of the percentage of mothers incarcerated range from
$59 \%$ to $80 \%$ of female prison populations (Berry \& Eigenberg, 2003; Luke, 2002; Mumola, 2000). Between 1991 and 2000, the number of incarcerated fathers increased by $60 \%$, while the number of incarcerated mothers increased by $87 \%$ (Mumola). Women are also more likely to have custody of children prior to incarceration, while the children of male offenders are more often being cared for by their female partners (Mumola; Schafer \& Dellinger, 1999).

Research shows that individuals with insufficient educational backgrounds and poor literacy skills are disproportionately represented within the criminal justice system (Greenberg, Dunleavy, \& Kutner, 2007; Harlow, 2003). Women inmates are more likely to have completed high school when compared to male inmates; however, like male inmates, women prisoners continue to be less educated than women found in the general population (Harlow). Educational attainment is strongly associated with economic well-being. Also, the continuing decrease in women's economic well-being, clearly demonstrated in the literature (Lieb \& Thistle, 2005; Ozawa \& Yoon, 2003), is especially true for incarcerated women with children.

Lieb and Thistle (2005) found that employment has a higher probability of increasing women's income when compared to marriage, and they emphasize the need for access to higher education and prime employment opportunities for women. Although education has been identified as one of the paths out of poverty, the Personal Responsibility and Work Opportunity Reconciliation Act of 1996 allows women only 12 months of vocational training while on welfare (Pandey, Zhan, Neely-Barnes, \& Menon, 2000). The U.S. correctional system has begun to acknowledge education as an effective crime prevention tool and is providing more educational opportunities and vocational training in juvenile detention facilities and adult prisons (Harlow, 2003; Harrison \& Beck, 2006).

Punitive drug policies, which include mandatory sentencing laws, have received partial blame for the increase in women prisoners (Bloom, 
Chesney-Lind, \& Owen, 1994; Covington, 2003; Travis \& Waul, 2003). Substance use and addiction has profoundly influenced the growth in the women offender population, with studies showing differences between female and male drug offenders. A study examining 4,509 women and 3,595 men participating in 15 prison-based drug treatment programs found that women had more severe drug histories (e.g., more frequent use, intravenous drug use) and more frequently reported cocaine/crack as the drug of choice. Powell and Nolan (2003) found that mothers in a California prison reported higher rates of drug use at the time of their offense when compared with fathers (mothers, 47\%; fathers, 37\%) and when compared with nonparents of either gender. Drug use is prevalent among female offenders and is more often an integral part of their criminal activity, particularly for property-related crimes, than it is for male offenders (Martin \& Bryant, 2001; Powell \& Nolan).

Issues stemming from intimate partner violence and mental health concerns related to prior childhood abuse are also seen as factors contributing to the rise in women offenders. Nearly $80 \%$ of female offenders with mental illnesses report prior physical or sexual abuse (Greenfield \& Snell, 1999). Over time, unresolved victimization provides a base for the development of physical and mental health problems (Covington, 2003; Messina, Bourdon, \& Prendergast, 2003), interfering with the capacity for self-sufficiency (Allen, Bybee, \& Sullivan, 2004; Anderson et al., 2003).

Compared to male offenders, women are more likely to write bad checks and commit property offenses than to perpetrate serious or violent offenses (Covington, 2003; Smart, 1995). Many researchers suggest that women are more often arrested and incarcerated for crimes that reflect social positioning based on race, gender, and class (Henriques \& Manatu, 2001). Those crimes include prostitution, larceny, shoplifting, check or credit card fraud, forgery, and drug possession (Chesney-Lind, Harris, \& deGroot, 1998; Ferraro \& Moe, 2003; Greenfield \& Snell, 1999; Immarigeon \& Chesney-Lind, 1992; Watterson, 1996).

\section{Differences in Women With and Without Partners and Children}

The literature also provides data on the psychosocial needs of incarcerated mothers (Boudin, 1998; Schafer \& Dellinger, 1999; Singer, Bussey, Song, \& Lunghofer, 1995), the challenge of parenting during incarceration (Adalist-Estrin, 1986; Enos, 2001; Houck \& Loper, 2000), the importance of family ties (Adalist-Estrin; Arditti \& Few, 2006; Bloom, 1992), and the relationship between motherhood and crime (Ferraro \& Moe, 2003), but few comparisons exist of inmates who are and are not mothers. One exception is a recent study (Loper, 2006) that examined the adjustment patterns and criminal characteristics of 516 women: 350 mothers and 166 nonmothers in a maximum-security women's prison. All of the mothers had at least one current or prior conviction for drug offenses. Nonmothers were more frequently convicted for homicide, and mothers were more frequently convicted for property or drug offenses.

Many studies report that women commit crimes in order to care for their children (Ferraro \& Moe, 2003; Henriques, 1982; Watterson, 1996). Ferraro and Moe's ethnographic study involved 30 women incarcerated in a southwestern state's county jail. The 27 women who were mothers had an average of three children, and these mothers saw crime as an alternative to hunger and homelessness and as a way to meet the physical needs of their children. Mothers often named economic hardship as a reason for their criminal behavior, while nonmothers more often referenced drugs and alcohol as the basis for their offenses.

Punitive public welfare structures, low-paying and unstable jobs, husbands and boyfriends who cannot or will not provide adequate financial support, and the absence of community-based supports are some of the many factors that can push women into lifestyles that bring them in contact with the criminal justice system (Edin \& Kefalas, 2004; Ferraro \& Moe, 2003). A study of nonincarcerated mothers on welfare supports the idea that some poor mothers turn to less-than-legitimate sources of financial support (selling drugs, sex, and stolen goods) when legitimate avenues have been exhausted (Edin \& Lein, 1997).

This research has begun to identify some of the conditions faced by women that draw them into criminal behavior. However, hampered by methodological issues, such as small sample sizes (Ferraro \& Moe, 2003) or failure to include a comparison group (Loper, 2006), research findings remain limited. The analysis reported here sampled 157 incarcerated women and an additional 266 women in the community, many of whom had histories of criminal behavior, in order to examine the conditions and behaviors of mothers and nonmothers, both partnered and single, to further determine the relationship between these women's roles and criminal acts and outcomes.

\section{Method}

The findings reported here are from a larger study seeking to understand women's experiences of victimization among a specific population of women, including a large population of incarcerated women (Postmus \& Severson, 2005). The researchers were interested in exploring the life trajectories of victimized women-including adult survival strategies, both legal and illegal-and possible involvement with the justice system. For purposes here, we specifically focus on the relationship between the roles of the women sampled and their criminal behavior.

\section{Sample}

Sampling occurred in 5 distinct communities in 1 Midwestern U.S. state: 3 urban, 1 rural, and 1 in the state's only correctional facility for women. Community referrals were generated through recruitment of women seeking assistance from sexual assault and domestic violence service providers and through posting flyers in places that women frequent, such as grocery stores and laundromats. Women were also recruited from flyers, printed in English and Spanish and distributed to social service agencies, and from advertisements in local newspapers; 23 women were interviewed in Spanish.

The total study sample included 423 women-157 from the prison, 157 generated from domestic violence and sexual assault programs, and 109 from the four communities at large.

Women age 18 and older and incarcerated in the state's women's correctional facility for at least 1 month were eligible to participate. These criteria were established to account for the sometimes frightening and chaotic experiences inmates endure during the first few weeks of incarceration (Browne, Miller, \& Maguin, 1999). There were no institutional restrictions to recruitment; thus, women housed throughout the prison were eligible for inclusion. Women in the agency sample had to have received domestic violence or sexual assault services in the prior 12 months $(n=157)$. The other community sample group was comprised of women in the same communities who had not received domestic violence or sexual assault services within the prior 12 months, recruited through public notice.

\section{Data Collection}

All women were able to give their informed consent or refusal to participate in the study without penalty from the prison or the agency from which they were solicited. Private, one-hour interviews of the incarcerated women were conducted on prison grounds over a 12-month period; 
women in the community were interviewed throughout the same 12 -month period in mutually agreed upon safe locations. Community participants were compensated with $\$ 25$. The incarcerated women were not allowed to receive such compensation; instead, these women were provided psychoeducational groups regarding violence, victimization, and planning for personal safety.

\section{Survey and Interview Measures}

We report here the measures used in this particular analysis of women's familial roles, victimization, economic supports, and illegal behavior.

Partnered women. The researchers asked women about with whom they had lived in the past 12 months-or, for those currently incarcerated, their housemates in the 12 months prior to their incarceration. Over half of the sample lived with an intimate partner; half of these were married, and half were living unmarried with a male partner (a small proportion, $3.5 \%$, reported living with a female partner; see Table 1 ).

Mothers. For the purposes of this study, mothers are those women who report having children under the age of 18 in response to "Do you have children?" A woman may or may not have included stepchildren or other children in her response; she was not asked to specify. Women indicated that they have children, how many children they have, and their children's ages (in groupings). The vast majority of women in this sample have children, and most have three or fewer children (see Table 1). The mean and median number of children per woman is two.

TABLE 1. Status of Sample in Regard to Wives and Mothers $(N=423)$

\begin{tabular}{|c|c|c|}
\hline ChARACTERISTICS & $\%$ & $f$ \\
\hline \multicolumn{3}{|l|}{ Wife status } \\
\hline Lived with boyfriend & 28.6 & 121 \\
\hline Lived with husband & 27.0 & 114 \\
\hline Lived with female partner & 3.5 & 15 \\
\hline \multicolumn{3}{|l|}{ Number of other adults in household: } \\
\hline None & 21.7 & 92 \\
\hline One & 60.0 & 254 \\
\hline Two & 15.8 & 67 \\
\hline Three & 1.9 & 8 \\
\hline Four & 0.5 & 2 \\
\hline \multicolumn{3}{|l|}{ Mother status } \\
\hline Have children & 81.1 & 343 \\
\hline \multicolumn{3}{|l|}{ Have children of age: ${ }^{a}$} \\
\hline Under 5 & 26.2 & 111 \\
\hline Between 5-12 & 42.8 & 181 \\
\hline Between 13-17 & 31.0 & 131 \\
\hline 18 or older & 30.7 & 130 \\
\hline \multicolumn{3}{|l|}{ Total number of children } \\
\hline None & 18.9 & 80 \\
\hline One & 19.4 & 82 \\
\hline Two & 25.5 & 108 \\
\hline Three & 18.7 & 79 \\
\hline Four & 9.2 & 39 \\
\hline Five & 5.4 & 23 \\
\hline Six & 2.1 & 9 \\
\hline Seven & 0.2 & 1 \\
\hline Eight & 0.2 & 1 \\
\hline Nine & 0.5 & 2 \\
\hline Mean number of children & 2.1 & $S D=1.6$ \\
\hline Lived with own children in past 12 months & 52.5 & 222 \\
\hline Have children under age 18 & 66.5 & 282 \\
\hline \multicolumn{3}{|l|}{ Partnered parent status } \\
\hline No children & 18.9 & 80 \\
\hline Single parent & 33.1 & 140 \\
\hline Children \& partner (unmarried) & 24.8 & 105 \\
\hline Children \& married & 23.2 & 98 \\
\hline
\end{tabular}

a Multiple responses.
Victimization. Given that the sample in this study includes women from prison and those who have received services for intimate partner violence, responses yield estimations of victimization and arrest rates higher than those among the general population. Detailed questions about victimization experiences were asked, also known to yield higher rates of victimization (Browne et al., 1999). This study does not attempt to estimate victimization rates for women in the general population, but to examine the relationship between experiences of victimization and outcomes.

Sexual and physical abuse during childhood and adolescence were measured using the Childhood Maltreatment Interview Schedule (Briere, 1992). While there are no known studies on overall reliability or validity, the use of this measure in pilot studies suggests predictive and construct validity (Briere). Given cautions about the use of the instrument's multiple questions in a summary fashion for research purposes (Briere), this analysis used only two summary questions from the Briere instrument: "To the best of your knowledge, before age 17, were you ever (a) sexually assaulted, (b) physically assaulted?" Each of these questions produced a yes or no answer.

The Abusive Behavior Inventory (ABI; Shepard \& Campbell, 1992) was used to measure intimate partner violence (IPV). Respondents were asked to estimate how often each victimization behavior occurs, on a scale of 1 (never) to 5 (very often). Psychological IPV is the mean score of 20 of the 30 items on the ABI having to do with psychological forms of control and humiliation; physical violence is the mean score of the remaining 10 items on the ABI having to do with physical forms of abuse. The alpha coefficient for physical IPV in this study is .92; for psychological IPV, the coefficient is .96.

Sexual assault in adulthood by an intimate partner, family member, or stranger was measured using the Sexual Experiences Survey (Koss \& Oros, 1982). This survey was developed to elicit unreported incidences of rape and sexual assault; data suggest that rape is often underreported (Koss \& Oros). Respondents were asked to indicate whether each of 10 violent items has ever occurred, and these were grouped into four categories: sexual coercion (four items), sexual assault (two items), and rape (four items). The alpha coefficient for internal consistency in the current study is .90 .

Economic supports. We also asked women about the types of activities in which they engaged for economic support, and women were given a list of seven categories of economic tactics, including a category of illegal activities. The illegal economic activities include writing bad checks, selling illegal drugs, providing sex for money, burglary, and begging/panhandling. The nonillegal activities include receiving gifts or loans, selling handmade items, providing a service, receiving welfare, and pawning items.

Arrest and incarceration. All women interviewed, whether incarcerated or not, were asked if they had ever been arrested and/or incarcerated. Including the 157 currently incarcerated women, a total of 285 women had ever been arrested, and 183 had ever been incarcerated.

Criminal behavior. Women were asked if they had ever been arrested; if they had been, they were asked about the nature of the arrest(s) for up to nine arrests. In this area of questioning, we know only about those behaviors for which the woman was arrested, not other criminal behaviors that went unnoticed. As to the arrest, we report here the initial type of arrest, not whether the woman had pled to a lesser or different charge. We categorized these arrests into larger categories, including economic (burglary, forgery, theft, auto theft, shoplifting, soliciting, panhandling, and bad checks), drug-related (selling drugs, drug trafficking, intent to sell, possession of drugs or paraphernalia, and drug manufacturing), 
and violent crimes (murder, robbery, battery, assault [aggravated or not], domestic violence, child abuse, and sexual assault).

\section{Analysis Plan}

This analysis compares "partnered" women (married or unmarried with partners) and "nonpartnered" women (without an adult intimate partner in the past 12 months-or, for incarcerated women, in the 12 months preceding their incarceration). It also compares women with and without children under the age of 18 . Ultimately, women are categorized into four types of family status: single mothers, mothers who are married, mothers who live unmarried with (primarily male) partners, and women without children (regardless of partnered status). Most of our analyses compare these four groups.

There are four logistic regression equations. Originally, we performed three regression analyses predicting the number of economic, drugrelated, or violent crimes for each woman in the sample, using key variables identified in the following results section. These regression analyses were not as robust as when we performed logistic regression analyses for each of these dichotomous variables: having ever been arrested for an economic, drug-related, or violent crime (rather than the number of crimes). Given information about the different types of illegal economic activities in which women could participate, regression analyses were performed to predict the number of illegal economic activities reported by women.

\section{Results}

These four groups of women differ demographically. While the mean age of the women in this study is 35 , those with no children are signifi-

Table 2. Economic Conditions for Women With Differing Parental Status

\begin{tabular}{|c|c|c|c|c|c|}
\hline & $\begin{array}{c}\text { TOTAL } \\
(N=423)\end{array}$ & $\begin{array}{l}\text { No CHILDREN } \\
(n=80)\end{array}$ & $\begin{array}{l}\text { SINGLE PARENT } \\
(n=140)\end{array}$ & $\begin{array}{l}\text { CHILDREN } \\
\& \text { PARTNER } \\
(n=105)\end{array}$ & $\begin{array}{l}\text { CHILDREN } \\
\text { \& MARRIED } \\
(n=98)\end{array}$ \\
\hline CHARACTERISTICS & $\%$ & $\%$ & $\%$ & $\%$ & $\%$ \\
\hline \multicolumn{6}{|l|}{ Employment } \\
\hline Ever worked full-time & 93.1 & 91.2 & 90.6 & 98.1 & 92.9 \\
\hline Ever worked part-time & 87.1 & 88.7 & 89.9 & 83.5 & 85.7 \\
\hline Ever worked $>40 \mathrm{hrs}$. $/ \mathrm{wk}$. & 79.8 & 78.5 & 81.3 & 81.7 & 76.5 \\
\hline Held 2nd or 3rd job & 55.3 & 63.7 & 57.6 & 56.7 & 43.9 \\
\hline \multicolumn{6}{|l|}{ Types of job, past year } \\
\hline Food service** & 29.0 & 34.2 & 21.6 & 39.4 & 24.5 \\
\hline Customer service & 18.1 & 15.2 & 14.4 & 26.9 & 16.3 \\
\hline Nursing & 17.1 & 13.9 & 15.8 & 18.3 & 20.4 \\
\hline Maid & 16.0 & 13.9 & 13.7 & 21.2 & 15.3 \\
\hline Retail & 15.5 & 24.4 & 15.1 & 9.6 & 15.3 \\
\hline Clerical /data entry & 14.3 & 15.2 & 14.4 & 17.3 & 10.2 \\
\hline Factory & 13.3 & 10.1 & 14.4 & 15.4 & 12.2 \\
\hline Child care & 11.0 & 17.7 & 10.8 & 9.6 & 7.1 \\
\hline Professional & 7.4 & 11.4 & 5.0 & 7.7 & 7.1 \\
\hline \multicolumn{6}{|l|}{ Annual income ${ }^{* * *}$} \\
\hline$\$ 0$ to $\$ 10,000$ & 51.3 & 46.3 & 60.6 & 61.9 & 30.9 \\
\hline$\$ 10,001$ to $\$ 15,000$ & 13.4 & 16.3 & 15.3 & 8.6 & 13.4 \\
\hline$\$ 15,001$ to $\$ 25,000$ & 17.7 & 21.3 & 18.2 & 12.4 & 19.6 \\
\hline$\$ 25,001$ to $\$ 35,000$ & 8.4 & 8.8 & 3.6 & 7.6 & 15.5 \\
\hline$\$ 35,001+$ & 9.3 & 7.5 & 2.2 & 9.5 & 20.6 \\
\hline \multicolumn{6}{|l|}{ Difficulty living on income ${ }^{* *}$} \\
\hline Not at all & 16.1 & 17.5 & 11.5 & 15.2 & 22.4 \\
\hline A little & 16.6 & 17.5 & 15.1 & 14.3 & 20.4 \\
\hline Somewhat & 22.0 & 31.3 & 18.7 & 16.2 & 25.5 \\
\hline Very & 22.7 & 20.0 & 22.3 & 29.5 & 18.4 \\
\hline Extremely & 22.5 & 13.8 & 32.4 & 24.8 & 13.3 \\
\hline
\end{tabular}

** Difference between groups is significant at .01 level. *** Difference between groups is significant at .001 level. cantly younger $(p<.05)$ and have attained the highest average level of education $(p<.01)$. As women increase in age in this sample, their number of children also increases $(p<.01)$, and their education increases $(p$ $<.001)$. A higher level of education is associated with a lower incidence of motherhood ( $r=-.17 ; p<.001)$, but not with partnered status.

There are also differences in ethnic origin and education between the four groups. Those women with no children are predominantly White, while those who are single mothers or mothers living with unmarried partners are disproportionately African American $(p<.001)$. Latinas are disproportionately married with children. About three quarters of the women in this sample have a high school diploma. Having a high school education is more common among older women in the sample and among White women. A high school education is least common among the Latina women in this sample. In this sample of women at risk, there is no correlation between level of education and current income; women's annual incomes increase only slightly with education level or age.

\section{Economic Circumstances of Wives and Mothers}

Mothers are no less likely than nonmothers to work outside the home. They have the same patterns of employment, and they seldom differ in the types of jobs they have held. Although we have data on the age of the woman at the time of the survey, we do not include age in many analyses, because the behaviors of interest are historical, and an association between a woman's current age and historical behavior is difficult to interpret. There are few differences between the four groups of women in their employment histories. Most of the women in this sample work, and work hard (see Table 3). The majority also live in poverty. More than half of the sample have worked full-time, worked part-time, worked more than 40 hours a week, and held a second or third job to survive economically. The job most commonly held is food service.

When it comes to economic well-being, however, there are obvious differences. It should not be surprising that the legal protections of marriage benefit women economically. Married women with children have significantly higher incomes $(p<.001)$, and they are significantly less likely than any other group to perceive living on their income as difficult $(p<.01)$. Single mothers report the lowest annual income and perceive the most difficulty in living on their incomes $(p<.01)$. A full $61 \%$ of those women living with an unmarried partner also report an annual income lower than $\$ 10,000$.

\section{Victimization}

While mothers who are married have higher incomes and perceive living on their incomes as less difficult than unmarried women, single parenthood and/or living unmarried with a partner carry the risk of economic hardship. Do these roles carry physical risks as well?

Beyond the high rates of victimization for all women (an artifact of sampling), mothers living with unmarried partners are the most likely of the four family status groups to have histories of victimization, and in multiple forms (see Table 3). Mothers living with an unmarried partner are most likely to indicate psychological IPV $(p<.01)$ and physical IPV $(p<.05)$. They are also the group with the most frequent psychological IPV $(p<.001)$ and physical IPV events $(p<.001)$. 
Single mothers are also a high-risk group. They report the highest rates of adult sexual violence (which may or may not be by an intimate partner), especially rape $(p<.01)$. Almost three quarters of single mothers report being raped, compared to about two thirds of other groups of women. Married women with children report the lowest rates of victimization in this sample.

\section{Other Risk Factors}

Mothers living with a partner, either married or unmarried, are slightly more likely than single women to report having an alcohol problem (n.s.). Those mothers living with an unmarried partner are significantly more likely than others to report having a drug problem $(p<.001)$.

\section{Economic Supports}

Women were asked if they had ever used each of a list of economic supports which were grouped into seven categories: (a) welfare, (b) money gift/loan, (c) informal economic activities, (d) illegal activities, (e) small business activities, (f) informal fee-for-cash, and (g) credit. The majority of this sample has received welfare benefits, with higher rates for mothers than for nonmothers $(p<.001)$. Mothers living with unmarried partners have the highest welfare rates $(87 \%)$; this was higher than that for single mothers (78\%).

The most common economic supports used are legitimate, involving economic support from family, friends, and/or intimate partners. There are few differences between groups in the use of these forms of economic support.

The riskiest economic supports are most used by mothers who live with an unmarried partner. This group of women has the highest rates

TABLE 3. Risk Factors for Women of Differing Parental Status

\begin{tabular}{|c|c|c|c|c|c|}
\hline Characteristics & $\begin{array}{c}\text { TOTAL } \\
(N=423)\end{array}$ & $\begin{array}{l}\text { No CHILDREN } \\
(n=80)\end{array}$ & $\begin{array}{l}\text { SINGLE PARENT } \\
(n=140)\end{array}$ & $\begin{array}{l}\text { CHILDREN } \\
\text { \& PARTNER } \\
(n=105)\end{array}$ & $\begin{array}{l}\text { CHILDREN } \\
\& \text { MARRIED } \\
(n=98)\end{array}$ \\
\hline History of victimization & $\%$ & $\%$ & $\%$ & $\%$ & $\%$ \\
\hline Any psychological IPV** & 97.4 & 92.6 & 98.6 & 100.0 & 96.9 \\
\hline \multirow[t]{2}{*}{ Any physical IPV* } & 91.5 & 85.2 & 94.3 & 95.2 & 88.8 \\
\hline & Pts. & Pts. & Pts. & Pts. & Pts. \\
\hline Psychological IPV score ${ }^{* * *}$ & 3.2 & 2.6 & 3.4 & 3.4 & 3.0 \\
\hline \multirow[t]{2}{*}{ Physical IPV score ${ }^{* * *}$} & 2.5 & 2.0 & 2.7 & 2.7 & 2.4 \\
\hline & $\%$ & $\%$ & $\%$ & $\%$ & $\%$ \\
\hline Any child sexual abuse & 58.0 & 53.1 & 57.9 & 61.9 & 58.2 \\
\hline Any child physical abuse & 50.5 & 45.7 & 53.6 & 50.5 & 50.0 \\
\hline \multirow[t]{2}{*}{ Age of first child abuse * } & 8.0 & 6.8 & 8.1 & 8.0 & 8.9 \\
\hline & $\%$ & $\%$ & $\%$ & $\%$ & $\%$ \\
\hline Any adult sexual coercion & 77.6 & 75.9 & 83.5 & 78.8 & 69.1 \\
\hline Any adult rape & 67.4 & 63.3 & 72.5 & 67.0 & 63.9 \\
\hline \multirow[t]{2}{*}{ Any adult attempted rape ${ }^{* *}$} & 50.6 & 43.0 & 60.9 & 51.5 & 41.2 \\
\hline & Pts. & Pts. & Pts. & Pts. & Pts. \\
\hline Sexual coercion score* & 2.1 & 2.0 & 2.3 & 2.2 & 1.8 \\
\hline Rape score ${ }^{*}$ & 2.1 & 1.9 & 2.3 & 2.1 & 2.0 \\
\hline Attempted rape score* & 0.8 & 0.7 & 1.0 & 0.8 & 0.7 \\
\hline Severity of sexual assault & 2.2 & 2.1 & 2.4 & 2.2 & 2.1 \\
\hline History of substance abuse & $\%$ & $\%$ & $\%$ & $\%$ & $\%$ \\
\hline Reports alcohol problem & 18.5 & 13.8 & 15.1 & 23.8 & 21.4 \\
\hline Reports drug problem*** & 27.7 & 17.5 & 21.6 & 41.9 & 29.6 \\
\hline Number of drugs used & 1.1 & 1.2 & 1.0 & 1.2 & 0.9 \\
\hline
\end{tabular}

Note. IPV = intimate partner violence. * Difference between groups is significant at .05 level. ** Difference between groups is significant at .01 level. ${ }^{* *}$ Difference between groups is significant at .001 level. of selling plasma for money $(p<.01)$, selling illegal drugs $(p<.01)$, providing sex for money $(p<.05)$, and pawning their own or their family's items $(p<.05)$. Their rates of writing bad checks, burglary, and panhandling are also the highest of the four groups (n.s.). These women are especially unlikely to use credit.

In addition to parental and partnered status, we examined the obvious correlates of economic well-being: age and education. The woman's age is frequently related to the tactics she has used for economic support. Receiving gifts from intimate partners occurs significantly more among younger women $(p<.05)$. Conversely, selling things previously purchased $(p<.001)$, selling items retrieved from dumpsters $(p<.001)$, selling something handmade $(p<.001)$, selling recyclables $(p<.01)$, using credit cards $(p<$ $.01)$ and credit card advances $(p<.01)$, receiving a loan from an intimate partner $(p<.05)$, and starting her own small business $(p$ $<.05$ ) occur more among older women (who also report more difficulty living on their incomes).

Having earned a high school diploma makes a woman significantly less likely to use certain economic strategies to survive, compared to those less educated. High school graduates are less likely to steal or burglarize for money $(p<.05)$, and much more likely to receive gift money from family or friends $(p<.05)$, swap goods for money $(p<.05)$, provide a service for money $(p<.001)$, and use their credit, through credit cards $(p<.001)$ or a second mortgage on their homes $(p<.05)$. Finally, in this high-risk sample of women who largely live in poverty, annual income and the difficulty of living on that income are not related to using illegal economic strategies.

\section{Arrests and Incarceration}

While 157 of the 423 women in this sample (37\%) were incarcerated at the time of the interview, more than two thirds of the entire sample has been arrested at least once (see Table 4). Before reviewing any associations between arrests, incarceration, and motherhood and/or partnered status, we will review the common criminal risk factors in this sample.

Youth. The younger the woman in this sample, the more likely it is that she has been arrested ( $r=$ $-.15 ; p<.05)$. Among only those arrested, younger current age is associated with a younger age at first arrest $(r=.54 ; p<.001)$. This sample thus reflects the national trend of women's criminal involvement beginning at earlier ages. Current age is not related to a history of arrest for drug-related and/or economic crimes. There is a relationship, however, between youth and arrest for a violent crime $(r=$ $.11 ; p<.05)$.

Education. Not having a high school education is a very important predictor of arrest in this sample. Those women without a high school education are significantly more likely to be arrested for economic crimes $(p<.01)$, and the crime is not typically shoplifting, but other more serious economic crimes such as theft $(p<.05)$. In addition, those women without a high school education are significantly more likely than high school graduates to be arrested for drug-related crimes $(p<.01)$ and have a higher number of drug-related arrests $(p<.001)$. Finally, the average age of first arrest for non-high 
school graduates in this sample is 21 , versus almost 24 for high school graduates $(p<.05)$.

Family role. Those mothers living with a partner, married or unmarried, have the highest incarceration rates, at $57 \%$ and $50 \%$, respectively. Single mothers have a significantly lower incarceration rate $(36 \%)$, followed by nonmothers $(31 \% ; p<.001)$. When comparing mothers to nonmothers, women with children are significantly more likely than nonmothers to have been arrested $(p<.001)$ and significantly more likely to have been incarcerated $(p<.01)$. They are also significantly more likely than nonmothers to have committed economic crimes $(p<.01)$, but not drug-related or violent crimes.

Similar to incarceration rates, arrest rates are significantly higher for mothers living with unmarried partners $(80 \%)$ than for any other group $(p<.001$; see Table 4$)$. Other mothers, either single $(68 \%)$ or married $(67 \%)$, have somewhat lower arrest rates, and those women with no children have the lowest arrest rate of all (51\%). While motherhood alone is not related to committing drug-related crimes, the higher the number of children in the woman's home, the greater the likelihood is that she has been arrested for a drug crime $(p<.05)$. However, the correlations between motherhood and arrests are strongest between a woman's number of children under age 18 and the woman being arrested for an economic crime $(p<.001)$ and being arrested more frequently for economic crimes $(p<.05)$. Women who have children reported that their first arrest occurred at an earlier age, on average, than nonmothers $(p<.01)$.

While there are no statistically significant differences between the four groups in the specific crime(s) for which women have been arrested, mothers living with unmarried partners are again at highest risk (see Table 5). This group consistently has the highest arrest rate for shoplifting, general economic crimes, domestic violence, murder, drug-related crimes (including selling, possession, and manufacturing), and driving under the influence (recall that mothers living with unmarried partners have especially high rates of substance abuse). Married mothers also have relatively high arrest rates for economic and drug-related crimes.

When the total number of arrests is calculated, economic crimes constitute the type of crime for which women are most frequently arrested. Among those women who have been arrested for any crime $(n=285)$, they have been arrested for economic crimes an average of 2.5 times, and arrested for drug-related crimes an average of 1.0 times. Again, mothers living with unmarried partners have the highest incidence of economic crimes, drug-related crimes, and DUIs.

\section{Predicting Arrest Activity}

Given the correlates of arrest, logistic regression analyses were performed to assess how well key characteristics and conditions predict the incidence of economic crime, drug crime, and violent crime. For each of these dependent variables, the following independent variables were entered: number of years of education, number of children under age 18 , has a husband, has an unmarried male partner, physical IPV score, rape score, and number of drugs reported as used. Both years of education and number of children, although known to be correlated, were originally entered in order to identify the stronger predictor. We used multinomial regression, given the levels of measurement of the dependent variables.

The results of these three logistic regression analyses demonstrate the model performs moderately well in predicting whether a woman has ever been arrested for an economic crime: $R^{2}=.15$ and $F=10.7$ $(p<.001)$. The independent variables that predict whether a woman has been arrested for an economic crime are a lower number of years of education, a higher number of drugs used, and a higher number of children under age 18. The model performs better in predicting drug arrests: $R^{2}=.18$ and $F=12.8(p<$ .001). The key independent variables predicting any drug arrests are the number of drugs used and the number of years of education. Finally, this model is a poor predictor of violent crime: $R^{2}=.04$ and $F=$ $2.3(p<.05)$. The only variable predictive of violent crime is the number of rape behaviors that a woman has experienced.

Given that many illegal activities can occur without an arrest, we assessed whether the same model of independent variables was predictive of illegal economic activities, whether arrested or not. Multiple regression analysis was performed to examine which of these independent variables are good predictors of the number of illegal economic activities the woman had reported using. This model has the best fit of all four models: $R^{2}=.34$ and $F=29.9(p$ $<.001)$. The independent variables that are predic-

\footnotetext{
** Difference between groups is significant at .01 level.
} 
tive of the number of illegal economic activities in which a woman has engaged are a higher number of drugs used, a higher number of children under age 18, a higher physical IPV score, and a lower number of years of education.

\section{Conclusion and Implications for Practice and Policy}

This study examines a large number of incarcerated and nonincarcerated women from a variety of social and economic conditions, and it uses a battery of instruments designed to gather detailed information about their maternal and marital status, their histories of economic and criminal behaviors, their histories of victimization, and their adult outcomes.

There are several limitations to the methodology, given the complexities of the subject matter and sample. The retrospective nature of this study, asking women to recall their histories of victimization as well as their prior economic and criminal behaviors over time, limits the veracity of their responses. However, the instruments and questions used to obtain these data are rigorous and concrete in nature. We posit that the recollection of discrete events-such as the number of arrests and/or incarcerations, the number and types of victimizations experienced, the number and types of economic supports a woman has used and strategies employed, and the number and types of drugs used-can be more accurately reported than recollections of feelings or expressions of victimization, etc. Nonetheless, the influence of social desirability and stigmatizing factors in the women's responses is unknown.

This study corroborates the knowledge that education is a protective factor for women and that women who complete their education and delay having children until their education is completed have better outcomes than those who do not. In analysis after analysis, those women who have more education and fewer children fare better than those who bear children at a young age and/or do not complete their education. The combination of motherhood and the constraints it imposes on women's employment options are strong contributors to women living in poverty. This is not surprising. What is surprising, and only now coming to light, are the contributions of early motherhood and poverty to the commission of illegal activities, particularly economic crimes. Right or wrong, for at least some mothers, these economically motivated crimes allow them to care for their children. Therefore, programs and practitioners seeking to assist new mothers at risk are advised to focus not only on parenting (for the benefit of the child), but on supporting the mother's ability to economically care for her child(ren) in ways that do not place her at increased risk for arrest and incarceration.

Is marriage a protective factor? The U.S. government has instituted a campaign to promote healthy marriage as a poverty-reduction strategy. Studies and reports, such as one issued from the National Center for Children in Poverty (Koball \& Douglas-Hall, 2005), reject the claim that marriage alone will greatly increase the economic security of a family, and they suggest instead a focus on programs that increase working parents' incomes and make opportunities for higher education more available and accessible. The findings of the study reported here support the claim that marriage, while providing some economic protection, does not entirely protect women from using illegitimate and illegal economic strategies. Whether married or not, motherhood and level of education are strong predictors of illegal economic activities and arrests. The financial responsibility for children assumed by poor women, whether partnered or not, appears to propel some women into a life of crime.

Whether married or not, as the women in this sample aged, their incomes did not increase accordingly. The majority of women held low-paying jobs and participated in less-than-legitimate economic tactics. Consequently, women are likely to be well served by policies and practices that focus on women's economic self-sufficiency through job training; subsidized day care; and fair hiring, promotion, and wage policies and practices (Sanders \& Schnabel, 2007).

Finally, this study highlights the intersection of victimization, poverty, and criminal behavior of women. The pursuit of marriage to bring women out of poverty does not address the level of violence that women experience in intimate partnerships. A woman's experience of violence by an intimate partner is a strong correlate of her use of illegal economic strategies. Further research that illuminates the dynamic that connects childhood and/or adult experience(s) of poverty and victimization with the types of criminal activities in which poor mothers engage is critical for the development of antiviolence, antipoverty strategies that are solidly footed in evidence.

In the early part of this article, we defined the context for discussing the findings of this research: the dramatic increases seen in women's arrest rates and the similarly dramatic growth in women's incarceration rates over the last 12 years. Our findings support those generated in prior research: arrested and incarcerated women report significant histories of childhood and adult victimization. This study details that partnered women who have histories of intimate partner violence, women who have children, and women who have achieved a lower level of education are at higher risk for arrest and incarceration. Many of these women turn to illegal strategies to support themselves and their children.

The widespread acknowledgment of the growing interface of women with the criminal justice system is alarming, but this knowledge presents an opportunity to develop methods of preventing an unmanageably large women's prison population and, of equal importance, methods of preventing a corresponding deleterious increase in the number of children whose mothers are incarcerated. This study provides evidentiary support for seizing the opportunity to offer the kinds of programs and services most likely to make a difference in these women's lives. They include programs that help to ensure higher levels of education for women, such as reduced fees, school accommodations for pregnant high-school-aged women, and creatively structured and accessible programs for women to complete their GEDs or to pursue higher education. In the same vein, greater access to educational opportunities, made available through women's shelters and other agencies serving women, will help women gain the level of education that this study and others have found to be so important to women's self-sufficiency. Programs developed to reduce the incidence of teenage pregnancy (and the consequences of early motherhood) contribute beneficially not only to women's long-term economic opportunities, but also to a decrease in risk for criminal activity and incarceration. Finally, changes in the laws mandating prison sentences for drugrelated crimes are required. Instead, programs and services that offer women opportunities to beat their addictions while remaining in the community are necessary to keep women and mothers successful in their personal and familial roles.

In summary, when it comes to women's involvement in the criminal justice system, educated and financially secure adult women and mothers fare better than their younger, less-educated, and poor sisters, even when they share substantial histories of victimization. While we may not be able to prevent every act of violence against women, this study points to the specific programs and services likely to mitigate some of the consequences of violence for wives and mothers, including those of arrest and incarceration. 


\section{References}

Adalist-Estrin, A. (1986). Parenting from behind bars. Family Resource Coalition Report, 1, 12-13.

Allen, N. E., Bybee, D. I., \& Sullivan, C. M. (2004). Battered women's multitude of needs: Evidence supporting the need for comprehensive advocacy. Violence Against Women, 10(9), 1015-1035.

Anderson, M. A., Gillig, P. M., Sitaker, M., McCloskey, K., Malloy, K., \& Grigsby, N. (2003). "Why doesn't she just leave?": A descriptive study of victim reported impediments to her safety. Journal of Family Violence, 18(3), 151-155.

Arditti, J. A., \& Few, A. L. (2006). Mothers' reentry into family life following incarceration. Criminal Justice Policy Review, 17(1), 103-123.

Beck, A. J. (2000). Prisoners in 1999 (Report No. 183476). Washington, DC: U.S. Dept. of Justice, Bureau of Justice Statistics.

Berry, P., \& Eigenberg, H. (2003). Role strain and incarcerated mothers: Understanding the process of mothering. Women and Criminal Justice, 77, 513-530.

Bloom, B. (1992). Incarcerated mothers and their children: Maintaining family ties. In American Correctional Association (Ed.), Female offenders: Meeting the needs of a neglected population (pp. 47-63). Laurel, MD: American Correctional Association.

Bloom, B., Chesney-Lind, M., \& Owen, B. (1994). Women in California prisons: Hidden victims of the war on drugs. San Francisco: Center on Juvenile and Criminal Justice.

Boudin, K. (1998). Lessons from a mother's program in prison: A psychosocial approach supports women and their children. In J. Harden \& M. Hill (Eds.), Breaking the rules: Women in prison and feminist therapy (pp. 103-125). New York: Haworth Press.

Briere, J. (1992). Child abuse trauma: Theory and treatment of the lasting effects. Newbury Park, CA: Sage.

Browne, A., Miller, B., \& Maguin, E. (1999). Prevalence and severity of lifetime physical and sexual victimization among incarcerated women. International Journal of Law and Psychiatry, 22, 301-322.

Chesney-Lind, M., Harris, M. K., \& deGroot, G. (1998). Female offenders. Corrections Today, 60(7), 66-144.

Covington, S. (2003). A woman's journey home: Challenges for female offenders. In J. Travis \& M. Waul (Eds.), Prisoners once removed: The impact of incarceration and reentry on children, families, and communities (pp. 67-103). Washington, DC: Urban Institute Press.

Dowden, C., \& Andrews, D. (1999). What works for female offenders: A metaanalytic review. Crime and Delinquency, 45(4), 438-352.

Edin, K. K., \& Kefalas, K.. (2004). Promises I can keep: Why poor women put motherhood before marriage. Berkeley, CA: University of California Press.

Edin, K. K., \& Lein, L. (1997). Making ends meet: How single mothers survive welfare and low wage work. New York: Russell Sage Foundation.

Enos, S. (2001). Mothering from the inside: Parenting in a women's prison. Albany NY: State University of New York Press.

Ferraro, K. J., \& Moe, A. M. (2003). Mothering, crime and incarceration. Journal of Contemporary Ethnography, 32(1), 9-40.

Greenberg, E., Dunleavy, E., \& Kutner, M. (2007). Literacy behind bars: Results from the 2003 national assessment of adult literacy prison survey (NCES Report No. 2007-473). Washington, DC: National Center for Education Statistics.

Greenfield, L., \& Snell, T. L. (1999). Special report: Women offenders (Report No. 175688). Washington, DC: Bureau of Justice Statistics.

Hairston, C. F. (1998). The forgotten parent: Understanding the forces that influence incarcerated fathers' relationships with their children. Child Welfare, 77(5), 617-639.

Hairston, C. F. (1991). Mothers in jail: Parent-child separation and jail visitation. Affilia, 6(2), 9-27.

Harlow, C. (2003). Education and correctional populations (Report No. 195670). Washington, DC: U.S. Dept. of Justice, Bureau of Justice Statistics.

Harrison, P. M., \& Beck, A. J. (2006). Prisoners in 2005 (Bureau of Justice Statistics Bulletin). Washington, DC: U.S. Dept. of Justice, Office of Justice Programs.

Henriques, Z. W. (1982). Imprisoned mothers and their children: A descriptive and analytical study. New York: University Press of America.

Henriques, Z. W., \& Manatu, R. N. (2001). Living on the outside: African American women before, during, and after imprisonment. The Prison Journal, 81(1), 6-19.

Houck, K. D., \& Loper, A. B. (2000). The relationship of parenting stress to adjustment among mothers in prison. American Journal of Orthopsychiatry, $72,548-558$.

Immarigeon, R., \& Chesney-Lind, M. (1992). Women's prisons: Overcrowded and overused. San Francisco: National Council on Crime and Delinquency.

Koball, H., \& Douglas-Hall, A. (2005, October). Marriage not enough to guarantee economic security. Retrieved September 28, 2008, from National Center for Children in Poverty, Columbia University Mailman School of Public Health Web site: http://www.nccp.org/publications/pub_632.html
Koss, M. P., \& Oros, C. J. (1982). Sexual experiences survey: A research instrument investigating sexual aggression and victimization. Journal of Counseling and Clinical Psychology, 50(3), 455-457.

Lieb, H., \& Thistle, S. (2005). The changing impact of marriage, motherhood and work on women's poverty. Journal of Women, Politics \& Policy, 27(3/4), 5-22.

Loper, A. B. (2006). How do mothers in prison differ from non-mothers? Journal of Child and Family Studies, 15(1), 83-95.

Luke, K. P. (2002). Mitigating the ill effects of maternal incarceration on women in prison and their children. Child Welfare, 81, 929-949.

Martin, S. E., \& Bryant, K. (2001). Gender differences in the association of alcohol intoxication and illicit drug abuse among persons arrested for violent and property offenses. Journal of Substance Abuse, 13, 563-581.

Messina, N., Bourdon, W., \& Prendergast, M. L. (2003). Assessing the needs of women in institutional therapeutic communities. Journal of Offenders Rehabilitation, 37(2), 89-106.

Mumola, C. (2000). Incarcerated parents and their children (Report No. 182335). Washington, DC: Bureau of Justice Statistics.

Ozawa, M., \& Yoon, H. (2003). Gender differences in the economic well-being of nonaged adults in the United States. Journal of Poverty, 7(1/2), 97-122.

Pandey, S., Zhan, M., Neely-Barnes, S., \& Menon, N. (2000). The higher education option for poor women with children. Journal of Sociology and Social Welfare, 27(4), 109-170.

Postmus, J. L., \& Severson, M. (2005). Violence and victimization: Exploring women's histories of survival. Washington, DC: National Institute of Justice.

Powell, M. A., \& Nolan, C. (2003). California state prisoners with children: Findings from the 1993 survey of inmates in state and federal correctional facilities (No. CRB 03-014). Sacramento, CA: California Research Bureau.

Richie, B. E. (2001). Challenges incarcerated women face as they return to their communities: Findings from life history interviews. Crime and Delinquency, $47,368-389$.

Sanders, C. K., \& Schnabel, M. (2007). Organizing for economic empowerment of battered women: Women's savings accounts. Journal of Community Practice, 14(3), 47-68.

Schafer, N. E., \& Dellinger, A. B. (1999). Jail parents: An assessment. Women and Criminal Justice, 10(4), 73-118.

Shepard, M. F., \& Campbell, J. A. (1992). The abusive behaviour inventory: A measure of psychological and physical abuse. Journal of Interpersonal Violence, 7(3), 291-305.

Singer, M. I., Bussey, J., Song, L. Y., \& Lunghofer, L. (1995). The psychosocial issues of women serving time in jail. Social Work, 40(1), 103-113.

Slaught, E. (1999). Family and offender treatment focusing on the family in the treatment of substance abusing criminal offenders. Journal of Drug Education, 19(1), 53-62.

Smart, C. (1995). Criminological theory: Its ideology and implications concerning women. In C. Smart (Ed.), Law, crime, and sexuality: Essays in feminism (pp. 16-31). London: Sage.

Stephan, J. J. (2001). Census of jails 1999 (Bureau of Justice Statistics Bulletin). Washington, DC: U.S. Dept. of Justice, Office of Justice Programs.

Travis, J., \& Waul, M. (2003). Prisoners once removed: The children and families of prisoners. In J. Travis \& M. Waul (Eds.), Prisoners once removed: The impact of incarceration and reentry on children, families, and communities (pp. 1-29). Washington, DC: Urban Institute Press.

Watterson, K. (1996). Women in prison: Inside the concrete womb. Boston: Northeastern University Press.

Marianne Berry, $\mathrm{PhD}$, is professor, Toni Johnson, $\mathrm{PhD}$, MSSW, is assistant professor, and Margaret Severson, MSW, JD, is associate professor, School of Social Welfare, University of Kansas. Judy L. Postmus, PhD, is assistant professor and director, Center on Violence Against Women \& Children, Rutgers University School of Social Work. Correspondence regarding this article can be sent to the first author at andysmom@ku.edu or School of Social Welfare, University of Kansas, 1545 Lilac Lane, Lawrence, KS 66044.

Manuscript received: February 1, 2008

Revised: June 13, 2008

Accepted: June 19, 2008

Authors' note. The research referenced in this article was funded by the National Institute of Justice (2003-IJ-CX-1037) with principal investigators Judy L. Postmus and Margaret Severson. Points of view in this document are those of the authors and do not necessarily represent the official position or policies of the U.S. Department of Justice. 